\title{
Diazonium Salts: Versatile Molecular Glues for Sticking Conductive Polymers to Flexible Electrodes
}

\author{
Momath Lo ${ }^{1,2,3}$, Rémi Pires ${ }^{3}$, Karim Diaw ${ }^{1}$, Diariatou Gningue-Sall ${ }^{1, *}$, Mehmet A. Oturan ${ }^{2}$, \\ Jean-Jacques Aaron ${ }^{2, *}$ and Mohamed M. Chehimi ${ }^{3, *}$ \\ 1 Faculté des Sciences, Université Cheikh Anta Diop, BP 5005 Dakar-Fann, Sénégal; \\ momath.lo@ucad.edu.sn (M.L.); karimdiaw@hotmail.com (K.D.) \\ 2 Laboratoire Géomatériaux et Environnement, Université Paris-Est, 5 Bd. Descartes, \\ 77454 Marne-la-Vallée CEDEX 2, France; mehmet.oturan@u-pem.fr \\ 3 Université Paris Est, CNRS, ICMPE (UMR 7182), 2-8 rue Henri Dunant, 94320 Thiais, France; \\ pires@icmpe.cnrs.fr \\ * Correspondence: diariatougningue.sall@ucad.edu.sn (D.G.-S.); jeanjacquesaaron@yahoo.fr (J.-J.A.); \\ chehimi@icmpe.cnrs.fr (M.M.C.); Tel.: +33-149-781-160 (M.M.C.)
}

Received: 20 June 2018; Accepted: 22 July 2018; Published: 8 August 2018

\begin{abstract}
Adhesion of polymers to surfaces is of the upmost importance in timely applications such as protective coatings, biomaterials, sensors, new power sources and soft electronics. In this context, this work examines the role of molecular interactions in the adhesion of polypyrrole thin films to flexible Indium Tin Oxide (ITO) electrodes grafted with aryl layers from various diazonium salts, namely 4-carboxybenzenediazonium (ITO- $\left.\mathrm{CO}_{2} \mathrm{H}\right)$, 4-sulfonicbenzenediazonium $\left(\mathrm{ITO}-\mathrm{SO}_{3} \mathrm{H}\right), 4-\mathrm{N}, \mathrm{N}$-dimethylbenzenediazonium (ITO-N $\left.\left(\mathrm{CH}_{3}\right)_{2}\right)$, 4-aminobenzenediazonium $\left(\mathrm{ITO}-\mathrm{NH}_{2}\right)$, 4-cyanobenzenediazonium (ITO-CN) and 4-N-phenylbenzenediazonium (ITO-NHPh). It was demonstrated that PPy thin layers were adherent to all aryl-modified surfaces, whereas adhesive failure was noted for bare ITO following simple solvent washing or sonication. Adhesion of polypyrrole was investigated in terms of hydrophilic/hydrophobic character of the underlying aryl layer as probed by contact angle measurements. It was found that sulfonic acid-doped polypyrrole (PPy-BSA) thin films were preferably deposited on the most hydrophobic surfaces. More importantly, the redox properties and electrochemical impedance of PPy were closely related to the hydrophobic character of the aryl layers. This work demonstrates that diazonium compounds are unique molecular glues for conductive polymers and permit to tune their interfacial properties. With robust, diazonium-based architectured interfaces, one can design high performance materials for e.g., sensors, printed soft electronics and flexible thermoelectrics.
\end{abstract}

Keywords: polypyrrole; diazonium salts; flexible ITO; adhesion; redox properties

\section{Introduction}

In the recent decades, conductive organic polymers have attracted a great deal of interest due to their salient features, namely electric, thermoelectric, electronic, optical, ion exchange, and reinforcing properties, to name but a few [1-3]. Particularly, polypyrrole (PPy) constitutes an excellent material for building electronic devices [4], because of its ease of preparation by a variety of chemical [5], electrochemical [6], biocatalytic [7], and radiation-induced [8,9] methods. In addition, it is possible to tune its electrical conductivity upon doping, copolymerization, blending and nanostructuring [10,11].

Several studies have been focused on the effects solvent nature [12], electrolyte [13], potential or current density [14,15], concentration of monomer [16], composition of working electrode (metals, glassy carbon, ITO) [17,18], on the electrochemical deposition and mechanical properties of PPy 
films. However, the performances as well as the long-term stability of polymer thin films is often limited by various factors, including poor adhesion to the substrate and migration of metal contamination from the substrate to the polymer [19]. To overcome these adhesion problems, coupling agents such as organosilanes and aryl layers from diazonium salts proved to efficiently anchor PPy [20-23] and other insulating polymers [24-26] to a large variety of materials surfaces. These coupling agents not only impart strong adhesive bonding to the conductive polymer top layer, but also limit or suppress the diffusion in the film of elements leached from the substrates [21].

While organosilanes are the main coupling agents used in adhesion science and technology [27-29], studies of diazonium salts as adhesion promoters remain sparse. This is due to the fact that the diazonium interface chemistry is still incipient. The interest of diazonium salts lies in their fast reaction with practically all surfaces, triggered by chemicals, reactive surfaces or radiations [30]. In addition, diazonium compounds are versatile as they impart functionalities to the materials surfaces depending on the nature of the substituent borne by the benzene ring in either para-, meta- or ortho- position of the diazonium group. In this way, one can design new surfaces possessing a plethora of properties such as hydrophilic/hydrophobic character [31], electrocatalytic activity [32], initiation of surface radical or oxidative polymerization [33-35], resistance to biofouling [36], sensing [37,38], reactivity towards polymer matrices [39,40].

However, to the best of our knowledge, no systematic study comparing the effect of several functional groups on the adhesion of diazonium-modified surfaces has been undertaken. Therefore, the objective of this work is to examine the propensity of a series of diazonium compounds to provide ultrathin adhesive layers to conductive polymer top coatings and to check to which extent the said aryl adhesive layers govern the physicochemical properties of the polymer top coatings. To illustrate the actual study, polypyrrole was selected as a reactive and functional polymer coating, and flexible ITO as a substrate which is generally difficult to coat with conductive polymers for obtaining long-term robust adhesion.

Herein, we investigated the electrografting of a series of diazonium compounds of the general formulae $\mathrm{N}_{2}-\mathrm{C}_{6} \mathrm{H}_{4}-\mathrm{R}$, with $\mathrm{R}$ in para position $=\mathrm{CO}_{2} \mathrm{H}, \mathrm{SO}_{3} \mathrm{H}, \mathrm{N}\left(\mathrm{CH}_{3}\right)_{2}, \mathrm{NH}_{2}, \mathrm{CN}$ and NH-Ph. The hydrophobic/hydrophilic character of aryl-modified ITO electrodes was probed by means of contact angle measurements of water drops. The modified flexible ITO sheets further served as platforms for the electrodeposition of benzene sulfonic acid-doped polypyrrole (PPy-BSA), and the electrochemical properties were interrogated by cyclic voltammetry and electrochemical impedance spectroscopy. The electrochemical properties of PPy-BSA coatings will be discussed in terms of surface composition and wettability of the underlying flexible aryl-modified ITO sheets.

\section{Materials and Methods}

\subsection{Reagents}

4-Aminobenzoic acid, 4-aminobenzene sulfonic acid, N,N-dimethyl-1,4-phenylenediamine, 1,4-phenylenediamine, 4-aminobenzonitrile, $N$-phenyl-4-phenylenediamine, were purchased from Sigma Aldrich. Sodium nitrite ( $\geq 99.0 \%$, Sigma-Aldrich, St. Louis, MO, USA), chloric acid $(37 \%)$, ferrocene (Sigma-Aldrich) and potassium chloride were used without further purification. Pyrrole (purity $\geq 98 \%$, Aldrich) and benzene sulfonic acid were refrigerated prior to synthesis. All aqueous solutions were prepared using Milli-Q ultrapure water $(\mathrm{MQ} 18.2 \mathrm{M} \Omega \cdot \mathrm{cm})$. ITO-coated polyethylene naphtalate (PEN) sheets (Peccel, Yokohama, Japan) were cut to $5 \times 10 \mathrm{~mm}$ with scissors and served as working electrodes.

\subsection{Diazonium Modification of Flexible ITO}

The diazonium cations were generated in situ from the parent aromatic amines. The aromatic amines and the corresponding modified electrodes ITO- $\mathrm{R}(\mathrm{R}=$ functional group) were the following: 4-aminobenzoic acid (ITO- $\left.\mathrm{CO}_{2} \mathrm{H}\right), 4$-aminobenzene sulfonic acid $\left(\mathrm{ITO}-\mathrm{SO} \mathrm{H}_{3} \mathrm{H}\right), \mathrm{N}, \mathrm{N}$-dimethyl-1,4- 
phenylenediamine (ITO-N $\left.\left(\mathrm{CH}_{3}\right)_{2}\right)$, 1,4-phenylenediamine(ITO- $\mathrm{NH}_{2}$ ), 4-aminobenzonitrile (ITO-CN), $N$-phenyl-p-phenylenediamine (ITO-NH-Ph). The ITO surface was cleaned by sonication in a mixture of water/ethanol 80:20 ( $v / v)$ for $2 \mathrm{~min}$. After sonication, the electrode was washed with DI water. The electrografting of aryl layers from the diazonium salts generated in situ was performed using a three-electrode system, including an ITO-coated polyethylene naphthalate (PEN) working electrode (area $\sim 5 \times 5 \mathrm{~mm}$ ), a stainless steel grid as counter electrode and a $\mathrm{Ag} / \mathrm{AgCl}$ (saturated $\mathrm{KCl}$ ) reference electrode.

The diazonium salt was produced by mixing 0.1 mmole of aromatic amine (equivalent to 13.7, 17.3, 13.6, 10.8, 11.8, or $18.4 \mathrm{mg}$ of 4-aminobenzoic acid, 4-aminobenzene sulfonic acid, $\mathrm{N}, \mathrm{N}$-dimethyl-1,4-phenylenediamine, 1,4-phenylenediamine, 4-aminobenzonitrile, or N-phenyl-4phenylenediamine, respectively) with $90 \mathrm{~mL}$ of $0.5 \mathrm{M} \mathrm{HCl}$ in a glass bath for $30 \mathrm{~min}$, before adding $10 \mathrm{~mL}$ of $10 \mathrm{mM} \mathrm{NaNO}_{2}$ aqueous solution (this $10 \mathrm{~mL}$ solution contains $0.1 \mathrm{mmol} \mathrm{NaNO}_{2}$ ). The resulting mixture was stirred for $1 \mathrm{~h}$. The electrografting was then carried out in potentiostatic conditions ( $-0.8 \mathrm{~V} / \mathrm{SCE}$ for $45 \mathrm{~s})$, using a Biologic SP 150 potentiostat (Seyssinet-Pariset, France), computer-controlled with an EC-lab software. The blocking effect of the bare and modified ITO electrodes was investigated in a $1 \mathrm{mM} \mathrm{Fe}(\mathrm{CN})^{3-/ 4-}$ redox solution by cyclic voltammetry $(\mathrm{CV})$ in the -0.4 and $0.6 \mathrm{~V} / \mathrm{SCE}$ range at a scan rate of $50 \mathrm{mV} \cdot \mathrm{s}^{-1}$. The relative electroactivity of the modified electrode, which is inversely related to its blocking effect properties, was quantified by CV in the presence of the redox probe species. The Parameter $I_{r e l}$ is defined as:

$$
I_{\text {rel }}=\frac{\text { Ipa with a film }}{\text { Ipa for a bare ITO }} \times 100
$$

where Ipa is the intensity of the anodic peak current. Electrochemical impedance spectroscopy measurements were performed at open circuit potential in $1 \mathrm{mM} \mathrm{K}_{3} \mathrm{Fe}(\mathrm{CN})_{6}$ and $0.1 \mathrm{M} \mathrm{KCl}$.

\subsection{Preparation and Electrochemical Characterization of Polypyrrole Films on Diazonium-Modified ITO}

Prior to the electropolymerization, diazonium-modified ITO electrodes were sonicated in a water/ethanol 80:20 ( $v / v)$ mixture for $2 \mathrm{~min}$. The PPy on the ITO modified aryl layer was prepared by electropolymerization in a $0.01 \mathrm{M}$ BSA $+0.1 \mathrm{M}$ pyrrole aqueous solution $(20 \mathrm{~mL})$ by CV in a potential range of -1.0 to $1.2 \mathrm{~V}$. The fresh PPy films were characterized by $\mathrm{CV}$ under the experimental conditions indicated in Section 3.

The impedance spectra were recorded in the $0.1 \mathrm{~Hz}$ to $100 \mathrm{kHz}$ frequency range.

\subsection{Surface Analysis}

The X-ray photoelectron spectra (XPS) were recorded using a K Alpha apparatus (Thermo Fisher Scientific, East Grinsted, UK) fitted with a monochromatic Al X-ray source (hv $=1486.6 \mathrm{eV}$; spot size $=400 \mu \mathrm{m})$. A flood gun was used for static charge compensation.

An Easy Drop Krüss instrument (Hamburg, Germany) was used to determine the contact angles of water drops deposited on diazonium-modified ITO and on PPy samples.

\section{Results and Discussion}

\subsection{Brief Description of the Strategy and the Objectives of the Work}

Six diazonium compounds of the general formulae $\mathrm{N}_{2}-\mathrm{C}_{6} \mathrm{H}_{4}-\mathrm{R}$, with $\mathrm{R}=\mathrm{CO}_{2} \mathrm{H}, \mathrm{SO}_{3} \mathrm{H}, \mathrm{N}\left(\mathrm{CH}_{3}\right)_{2}$, $\mathrm{NH}_{2}, \mathrm{CN}$ and $\mathrm{NH}-\mathrm{Ph}$, were selected for the preparation of aryl layers on flexible ITO surfaces. Electrochemistry was selected as a means of attaching aryl monolayers, because it is a simple and straightforward method which can be conducted in aqueous medium. Diazonium compounds were generated in situ from the commercially-available parent aromatic amines; this adds up to the versatility of chemical surface engineering with diazonium compounds. The choice of the functional group in para position of the diazonium depends on two criteria: the electron-donor or electron-acceptor character of 
the functional group, on the one hand, and its propensity to govern the wetting of ITO surfaces, on the other hand.

Figure 1 depicts the chemical structures of the in situ generated diazonium cations (Upper panel) and the simple strategy adopted to attach PPy in two steps (Lower panel). Attachment of an aryl adhesive layer was followed by electrodeposition of PPy. It is to note that no physicochemical study will be provided on the adhesion of PPy on bare ITO, which is known to be very poor, as previously reported [22]. Instead, we will concentrate the present investigation on the diazonium susbstituent effect on the PPy adhesion and its redox behaviour.

Hereafter, the study is split into three main sections: (i) attachment and properties of aryl layers, (ii) electropolymerization and behaviour of the PPy topcoat, and (iii) adhesion aspects of PPy top coat to modified ITO sheets.

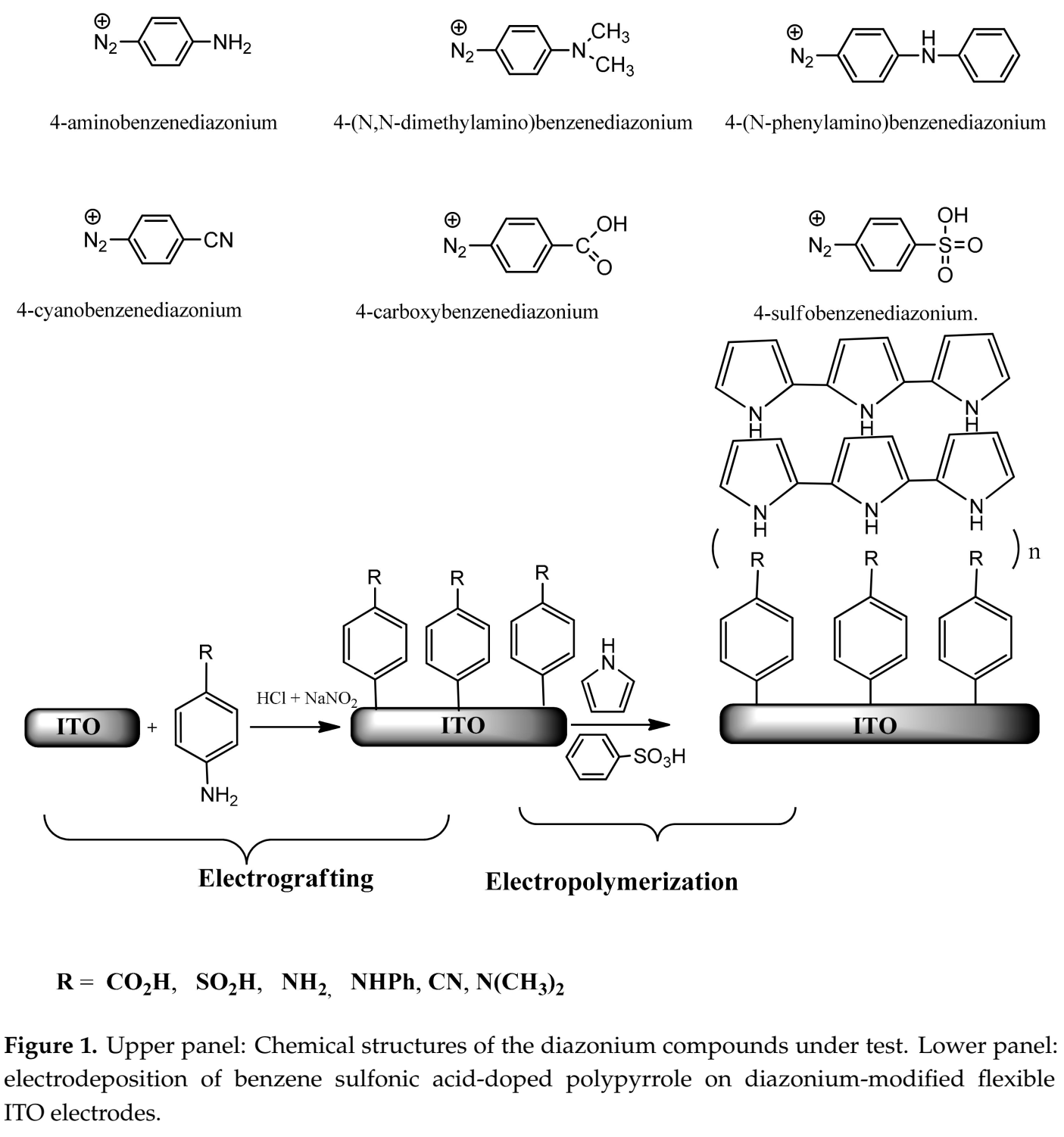

\subsection{Electrochemical Modification of Flexible ITO Sheets with Diazonium Salts}

Aryl layers were electrografted by chronoamperometry by setting the potential to $-0.8 \mathrm{~V} / \mathrm{SCE}$ for $45 \mathrm{~s}$. This electrografting period of time was sufficient for good polypyrrole adhesion without inducing any major blocking effect that hampers the deposition of the polymer [22,41]. The blocking effect of the aryl layers was assessed using $\mathrm{Fe}(\mathrm{CN})_{6}{ }^{3-/ 4-}$, as depicted in Figure 2. The quasi-reversible redox wave obtained with bare ITO (Figure $2 \mathrm{~A}(\mathrm{a})$, peaks at 0.25 and $0.1 \mathrm{~V}$ ) suffered a decrease in the 
intensity for ITO-N $\left(\mathrm{CH}_{3}\right)_{2}$ (Figure $2 \mathrm{~A}(\mathrm{~b})$, peaks at 0.38 and $0.1 \mathrm{~V}$ ), but disappeared quasi-completely in the case of ITO- $\mathrm{SO}_{3} \mathrm{H}$ (Figure $2 \mathrm{~A}(\mathrm{c})$ ), indicating a blocking effect of the aryl layer as reported by several authors [22,42-47]. The relative $\mathrm{Fe}(\mathrm{CN})_{6}{ }^{3-/ 4-}$ redox peak intensity $\left(\mathrm{I}_{\text {rel }}\right)$ decreased in the order ITO $>$ ITO-N $\left(\mathrm{CH}_{3}\right)_{2}>$ ITO-NH ${ }_{2}>$ ITO-NH-Ph $>$ ITO-CN $>$ ITO- $\mathrm{CO}_{2} \mathrm{H}>$ ITO-SO $3 \mathrm{H}$ (see Table 1). The influence of the aryl grafting to ITO electrodes is thus straightforward since the response of $\mathrm{Fe}(\mathrm{CN})_{6}{ }^{3-/ 4-}$ is flattened for modified ITO plates compared to bare ITO strips. From measurements similar to those of Figure 2A, $I_{\text {rel }}$ values were computed and reported in Table 1 for all aryl layers. The ITO-N $\left(\mathrm{CH}_{3}\right)_{2}$, ITO-NH-Ph and ITO- $\mathrm{NH}_{2}$ surfaces exhibit a blocking effect for $\mathrm{Fe}(\mathrm{CN})_{6}{ }^{3-/ 4-}$ redox system reactions with $I_{\text {rel }}$ values of $49,46.7,23.6 \%$, respectively. The highest blocking effects correspond to ITO-CN, ITO-CO ${ }_{2} \mathrm{H}$ and ITO-SO ${ }_{3} \mathrm{H}$, with $I_{\text {rel }}$ values of $15.7,11.2$ and $3.9 \%$, respectively. Under the

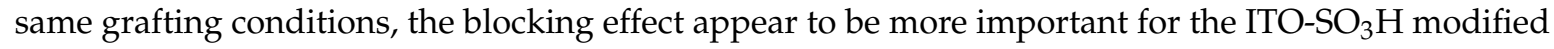
electrode [48].
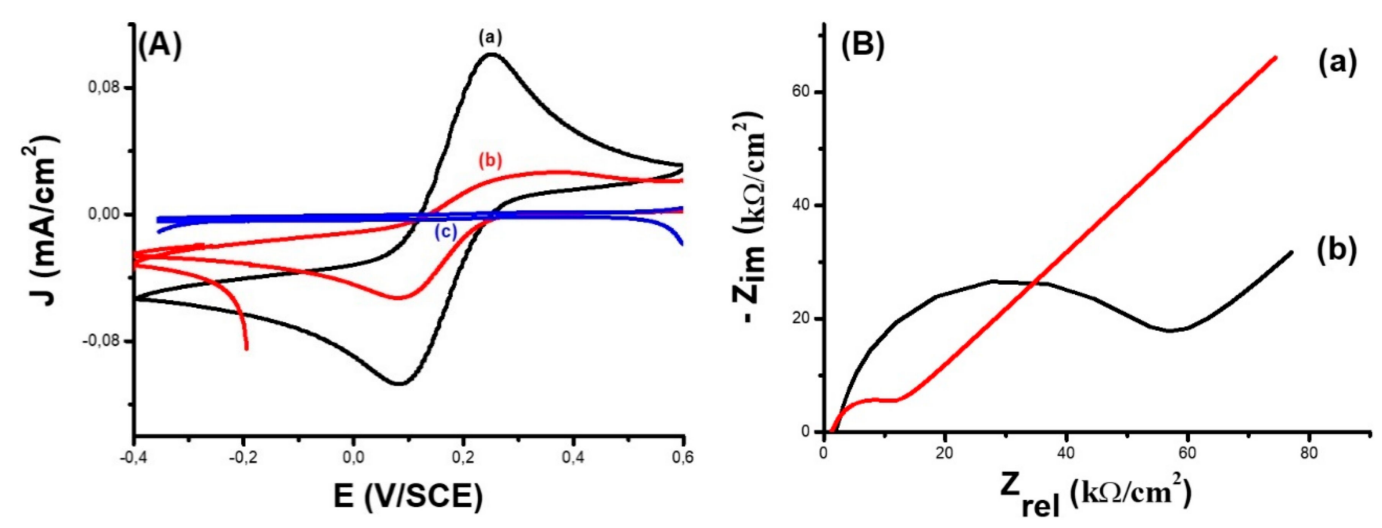

Figure 2. Electrochemical characterization of diazonium-modified ITO electrodes determined in aqueous solutions of $1 \mathrm{mM} \mathrm{K}_{3} \mathrm{Fe}(\mathrm{CN})_{6}$ and $0.1 \mathrm{M} \mathrm{KCl}$. (A) Typical cyclic voltammograms (a) bare ITO, (b) ITO-N $\left(\mathrm{CH}_{3}\right)_{2}$, and (c) ITO-SO $\mathrm{S}_{3} \mathrm{H}$. (B) Electrochemical impedance spectroscopy plots recorded with (a) ITO-N $\left(\mathrm{CH}_{3}\right)_{2}$, and (b) ITO-SO ${ }_{3} \mathrm{H}$.

Table 1. $I_{r e l}, R_{\mathrm{ct}}$ and water drop contact angles $(\theta)$ obtained for aryl-modified ITO.

\begin{tabular}{cccc}
\hline Surface & $\boldsymbol{I}_{\boldsymbol{r e l}} \mathbf{( \% )}$ & $\boldsymbol{R}_{\mathbf{c t}}\left(\mathbf{k} \Omega / \mathbf{c m}^{\mathbf{2}}\right)$ & $\boldsymbol{\theta}\left({ }^{\circ}\right)$ \\
\hline $\mathrm{ITO} \mathrm{SO}_{3} \mathrm{H}$ & 3.90 & 68.8 & $48.7 \pm 0.5$ \\
ITO-CO ${ }_{2} \mathrm{H}$ & 11.2 & 47.3 & $70.7 \pm 0.4$ \\
ITO-CN & 15.7 & 44.0 & $81.2 \pm 0.3$ \\
ITO-NH-Ph & 23.6 & 9.32 & $103.1 \pm 0.3$ \\
ITO-NH & 46.6 & 8.97 & $116 \pm 0.4$ \\
ITO-N $\left(\mathrm{CH}_{3}\right)_{2}$ & 48.6 & 7.15 & $136.7 \pm 0.1$ \\
\hline
\end{tabular}

The Nyquist plots for ITO-SO ${ }_{3} \mathrm{H}$ and ITO-N $\left(\mathrm{CH}_{3}\right)_{2}$ electrodes (Figure 2B) present typical semicircle shapes in the high-frequency domain, characteristic of an interfacial charge-transfer mechanism. The surfaces exhibit straight lines in the low-frequency regime, characteristic of a semi-infinite diffusion phenomenon. ITO-N $\left(\mathrm{CH}_{3}\right)_{2}$ displays the lowest charge transfer resistance $\left(R_{\mathrm{ct}}\right)$, ca. $7.15 \mathrm{k} \Omega / \mathrm{cm}^{2}$ compared to $68.8 \mathrm{k} \Omega / \mathrm{cm}^{2}$ for $\mathrm{ITO} \mathrm{SO}_{3} \mathrm{H}$, a trend that is in agreement with previously-reported studies on glassy carbon electrodes [48]. Table 1 reports $R_{\mathrm{ct}}$ values for all diazonium-modified ITO surfaces and clearly indicates the general following trend: low values for electron-donor aryl groups $\left(7.15-9.32 \mathrm{k} \Omega \mathrm{cm}^{2}\right)$ and $\sim 5-10$-fold higher $R_{\mathrm{ct}}$ values $\left(44.0-68.8 \mathrm{k} \Omega \mathrm{cm}^{2}\right)$ for electron-acceptor aryl groups.

Figure 3 shows images of water drops deposited on the various ITO-R surfaces. For $\mathrm{R}=\mathrm{N}\left(\mathrm{CH}_{3}\right)_{2}, \mathrm{NH}_{2}$ and $\mathrm{NH}-\mathrm{Ph}$, the contact angles were found to be $136.7 \pm 0.1,116 \pm 0.4$ and $103.1 \pm 0.3^{\circ}$, respectively. Taking into account the accepted rule of thumb, the water contact angle $(\theta)$ values above $90^{\circ}$ indicated 
hydrophobic surfaces. In contrast, more wetting was observed for the electron-acceptor groups $\mathrm{R}=\mathrm{CN}, \mathrm{COOH}$ and $\mathrm{SO}_{3} \mathrm{H}$, the water contact angles of which are $81.2 \pm 0.3,70.7 \pm 0.4$ and $48.7 \pm 0.5^{\circ}$, respectively. These surfaces can thus be ranked as relatively hydrophilic $\left(\theta<90^{\circ}\right)$. As expected, the layers with more ionizable groups $\mathrm{COOH}$ and $\mathrm{SO}_{3} \mathrm{H}$ produced the lowest contact angles and thus led to the highest hydrophilicity. It is thus possible to control the hydrophobic/hydrophilic character of flexible ITO surfaces by simply changing the radical $\mathrm{R}$ in para position of the diazonium group.

(a)

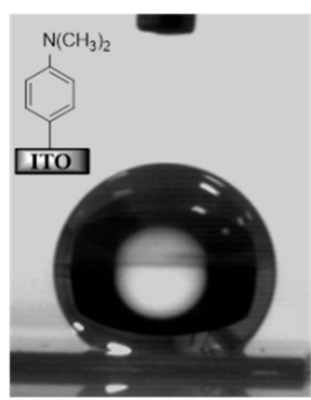

(d)

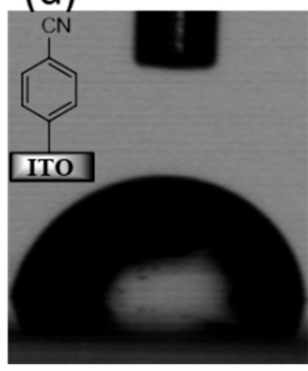

(b)

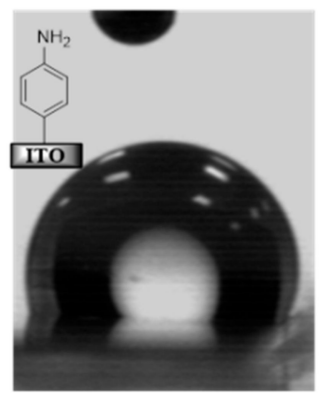

(e)

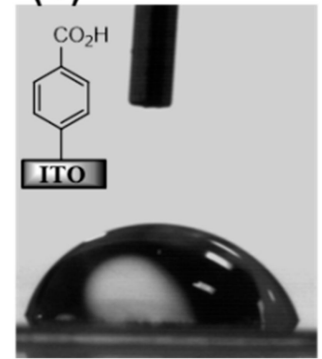

(c)

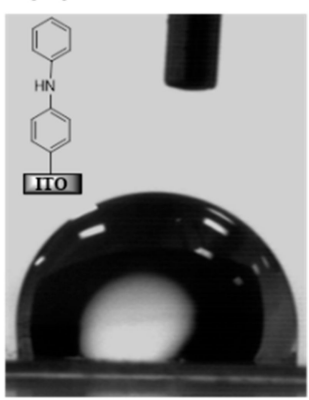

(f)

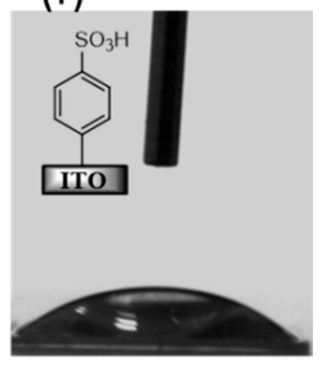

Figure 3. Contact angles of water drops gently deposited on diazonium-modified ITO: (a) ITO-N( $\left.\mathrm{CH}_{3}\right)_{2}$, (b) ITO-NH${ }_{2}$, (c) ITO-NH-Ph, (d) ITO-CN, (e) ITO-CO ${ }_{2} \mathrm{H}$, (f) ITO-SO ${ }_{3} \mathrm{H}$.

Figure 4 displays plots of the electrochemical characteristics of the aryl layers versus their wetting property, expressed by the water drop contact angle values. For the hydrophilic surfaces, the barrier to the $\mathrm{Fe}(\mathrm{CN})_{6}{ }^{3-/ 4-}$ probe is most probably due to the favourable water-aryl interfacial interactions. Under such wetting conditions, the probe molecules hardly reach the aryl-modified ITO surfaces and undergo redox reactions. Higher $I_{\text {rel }}$ values indicate weaker barrier, and the probe interact more favorably with the surfaces compared to water.
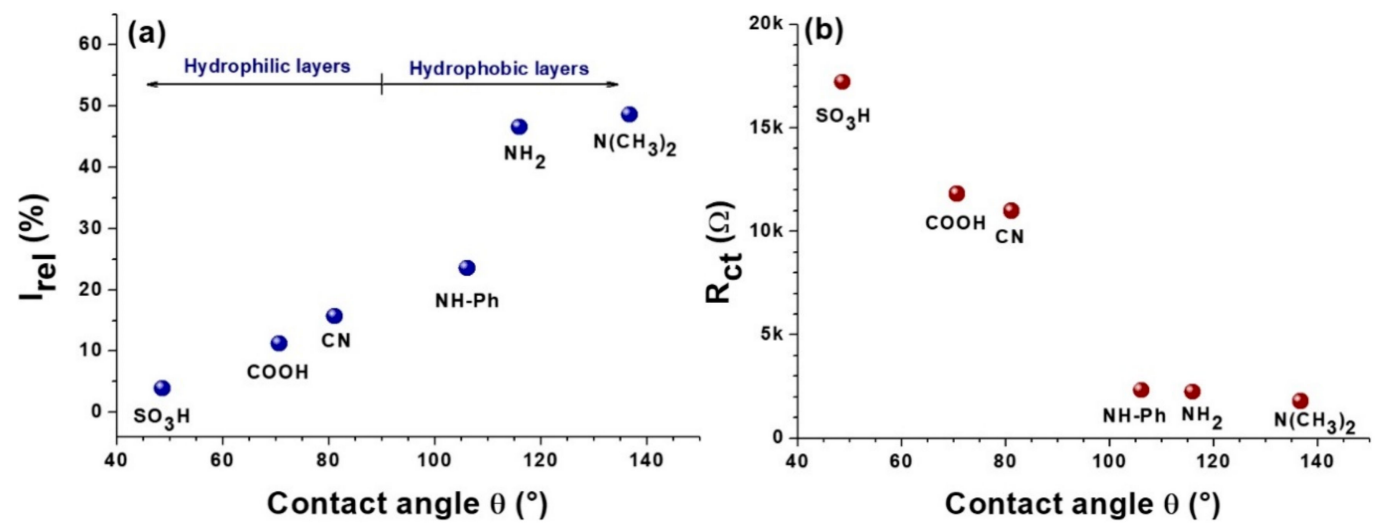

Figure 4. Correlations between the electrochemical and wetting properties of diazonium-modified flexible ITO electrodes: (a) $I_{r e l}$-vs-water contact angle; and (b) $R_{\mathrm{ct}}$-vs-water contact angle. 
As far as $R_{\mathrm{ct}}$ is concerned, this physical property decreases for hydrophobic aryl-modified ITO surfaces $\left(\theta>90^{\circ}\right)$. These results are due to the steric hindrance or the physical barrier role played by the free pair of the organic molecules [48].

All in one, the results can be discussed in terms of hydrophobic/hydrophilic effects [49]. Indeed, $\mathrm{Fe}(\mathrm{CN})_{6}{ }^{3-/ 4-}$ redox probe is relatively hydrophilic [49] and can rather interact with water instead of the aryl-modified surface. In addition, the hydrophilic aryl groups are negatively charged which may add up electrostatic repulsions at the ITO-aryl/probe interface.

\subsection{Electrodeposition of Polypyrrole on ITO}

3.3.1. Electrochemical Characterization of Poly(pyrrole-benzene sulfonic acid) Films on Aryl-Modified ITO

The aryl layers served as a primer for the electrodeposition of PPy-BSA. We achieved the electropolymerization on aryl-modified ITO strips by performing ten potential scanning cycles between -1 and $1.2 \mathrm{~V} / \mathrm{ECS}$ at $100 \mathrm{mV} \cdot \mathrm{s}^{-1}$ in an aqueous solution of $0.1 \mathrm{M}$ of pyrrole and $0.01 \mathrm{M}$ BSA (Figure 5). Table 2 reports the $E p_{\text {ox }}$ and $E p_{\text {red }}$ values for the electropolymerization process together with the oxidation peak density $\left(\mathrm{Jp}_{\mathrm{ox}}\right)$. Highly uniform and adherent PPy-BSA films were easily obtained on all modified electrodes, regardless the nature of the diazonium compound. The films obtained on the hydrophobic surfaces (ITO-N $\left(\mathrm{CH}_{3}\right)_{2}, \mathrm{ITO}-\mathrm{NH}_{2}, \mathrm{ITO}-\mathrm{NH}-\mathrm{Ph}$ ) were much more conductive than those obtained on the hydrophilic surfaces (ITO- $\mathrm{CO}_{2} \mathrm{H}, \mathrm{ITO}-\mathrm{SO}_{3} \mathrm{H}, \mathrm{ITO}-\mathrm{CN}$ ), as deduced from the corresponding high current in the CV curves.
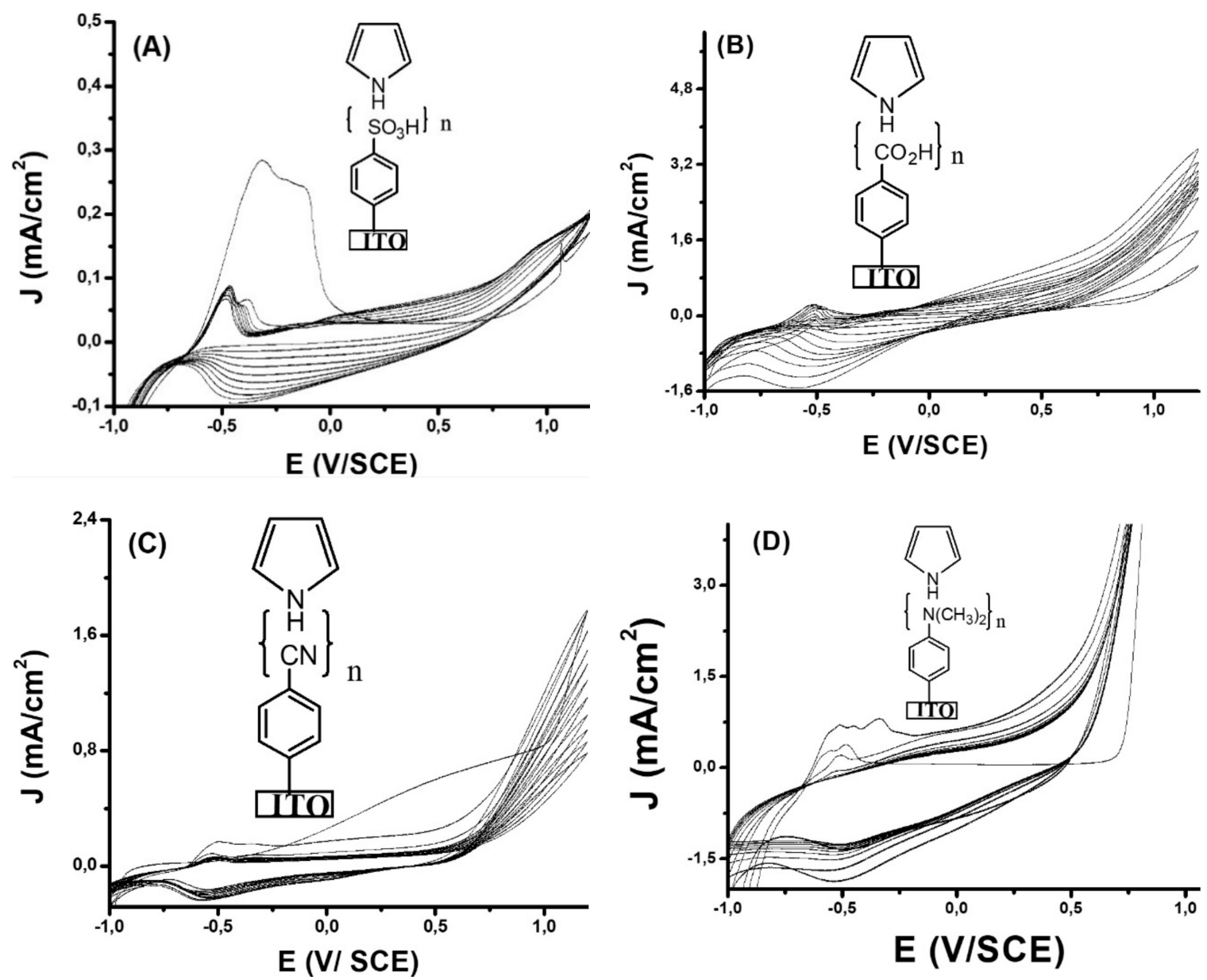

Figure 5. Cont. 

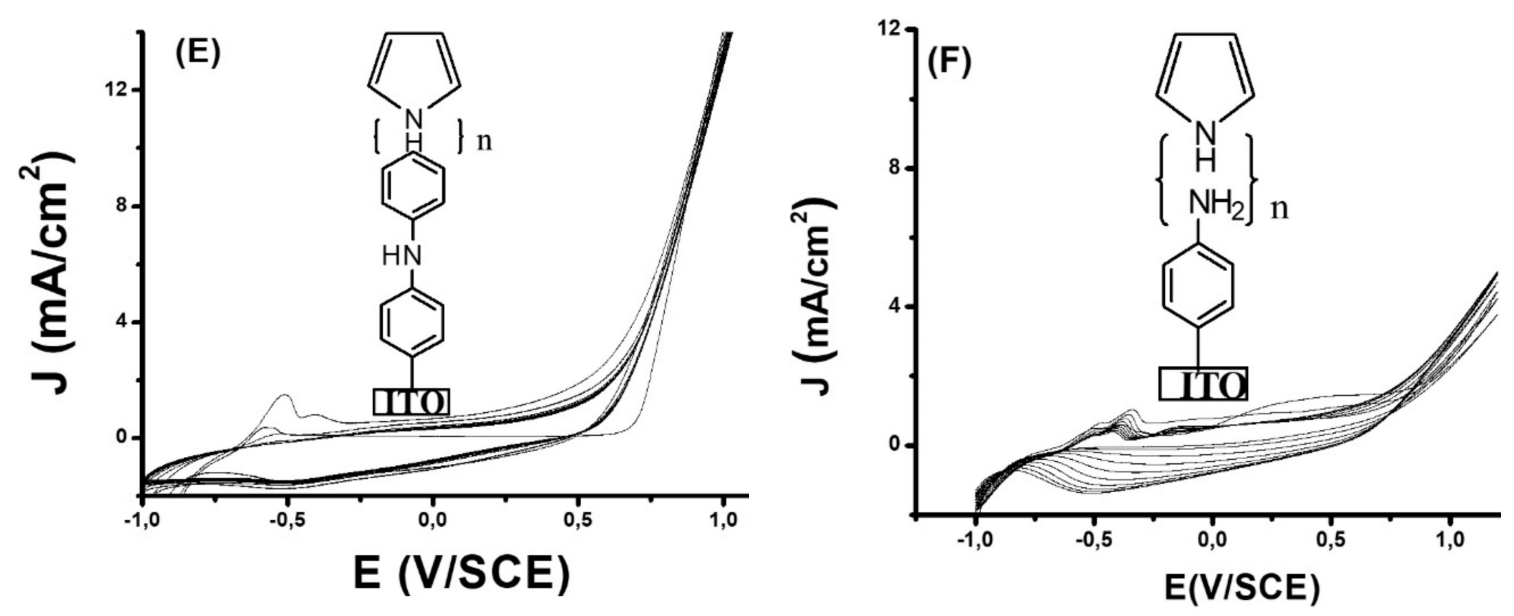

Figure 5. Electrosynthesis of PPy-BSA films by cyclic voltammetry on (A) ITO-SO 3 H; (B) $\mathrm{ITO}-\mathrm{CO}_{2} \mathrm{H}$; (C) ITO-CN; (D) ITO-N(CH$)_{2}$; (E) ITO-NH-Ph; and (F) ITO-NH $\mathrm{N}_{2}$.

Table 2. Electrochemical characteristics of electrodeposition of polypyrrole top layers: $E_{\mathrm{ox}}, E_{\mathrm{red}}$ and $J p_{\text {ox }}$ values for the 6 ITO-aryl electrode materials.

\begin{tabular}{cccc}
\hline Electrode Material & $\boldsymbol{E}_{\mathbf{o x}}(\mathbf{V})$ & $\boldsymbol{E}_{\text {red }}(\mathbf{V})$ & $\boldsymbol{J} p_{\mathbf{o x}}\left(\boldsymbol{\mu A} / \mathbf{c m}^{2}\right)$ \\
\hline ITO-N $\left(\mathrm{CH}_{3}\right)_{2}$ & 0.25 & -0.53 & 972 \\
ITO-NH 2 & 0.27 & -0.52 & 960 \\
ITO-NH-Ph & 0.2 & -0.5 & 936 \\
ITO-CN & 0.25 & -0.58 & 208 \\
ITO-CO ${ }_{2} \mathrm{H}$ & 0.41 & -0.59 & 908 \\
ITO-SO $3 \mathrm{H}$ & 0.24 & -0.43 & 228 \\
\hline
\end{tabular}

As a matter of fact, the oxidation peak is centered at $0.25,0.27$, and $0.2 \mathrm{~V} / \mathrm{SCE}$ for ITO-N $\left(\mathrm{CH}_{3}\right)_{2}$, ITO-NH $\mathrm{N}_{2}$ and ITO-NH-Ph electrodes, respectively. These peaks are positioned near those obtained on the hydrophilic surfaces ITO-CN and ITO- $\mathrm{SO}_{3} \mathrm{H}(0.25$ and $0.24 \mathrm{~V} / \mathrm{SCE}$, respectively). In contrast, on ITO- $\mathrm{CO}_{2} \mathrm{H}$ the oxidation peak is centred at a higher potential value $(0.41 \mathrm{~V} / \mathrm{SCE})$ and the reduction peak at $-0.59 \mathrm{~V} / \mathrm{SCE}$. This is the largest potential difference for the electropolymerization of pyrrole on the actual series of diazonium-modified ITO electrodes. The density of $\mathrm{Jp}_{\mathrm{ox}}$ of PPy-BSA on electrodes materials takes the maximum values for hydrophobic surface $\left(972 \mu \mathrm{A} / \mathrm{cm}^{2}\right.$ on ITO-N $\left.\left(\mathrm{CH}_{3}\right)_{2}\right)$, hence the highest conductivity achieved for electropolymerization of pyrrole on the actual electrode materials.

The results obtained so far show that thin films of PPy were preferentially deposited on hydrophobic surfaces, in line with the literature [50,51].

Figure 6 shows the blocking effect and EIS results of PPy films on all aryl-modified ITO electrodes. The blocking effect of PPy on all aryl layers was assessed with $\mathrm{Fe}(\mathrm{CN})_{6}^{3-/ 4-}$, as depicted in Figure 6A. The quasi-reversible redox couple (located at $0.25 \mathrm{~V}$ and $0.1 \mathrm{~V}$ ) obtained on the hydrophobic surfaces was characterized by a higher current, which accounted for a more conductive surface. It is worth to note that the PPy coating on ITO-N $\left(\mathrm{CH}_{3}\right)_{2}, \mathrm{ITO}-\mathrm{NH}_{2}$, ITO-NH-Ph (Figure 6B) exhibited the lowest charge transfer resistance $\left(0.15,0.36,0.6 \mathrm{k} \Omega / \mathrm{cm}^{2}\right.$, respectively). Moreover, the $\mathrm{R}_{\mathrm{ct}}$ increased for PPy on ITO- $\mathrm{SO}_{3} \mathrm{H}$, ITO- $\mathrm{CO}_{2} \mathrm{H}$, and ITO-CN; the impedance curves were significantly broadened and the semi-circle diameters were about $28.59,21.44$ and $10 \mathrm{k} \Omega / \mathrm{cm}^{2}$ respectively. These results indicated that $\mathrm{ITO}-\mathrm{SO}_{3} \mathrm{H}$ had the largest obstruction, which resulted in reducing electron-transfer rate or increasing resistance to the flow of electrons. Furthermore, EIS showed that charge transfer resistance of ITO-N( $\left(\mathrm{CH}_{3}\right)_{2}$-PPy was much lower compared to others.

The results reported so far stress the paramount importance of the hydrophobic character of the substrate, here imparted by the aryl layers. As a matter of fact, PPy is relatively hydrophobic, 
and preferentially binds to hydrophobic surfaces [52]. Conversely, the strength of (macro) moleculepolypyrrole molecular interactions are maximized in water [53].
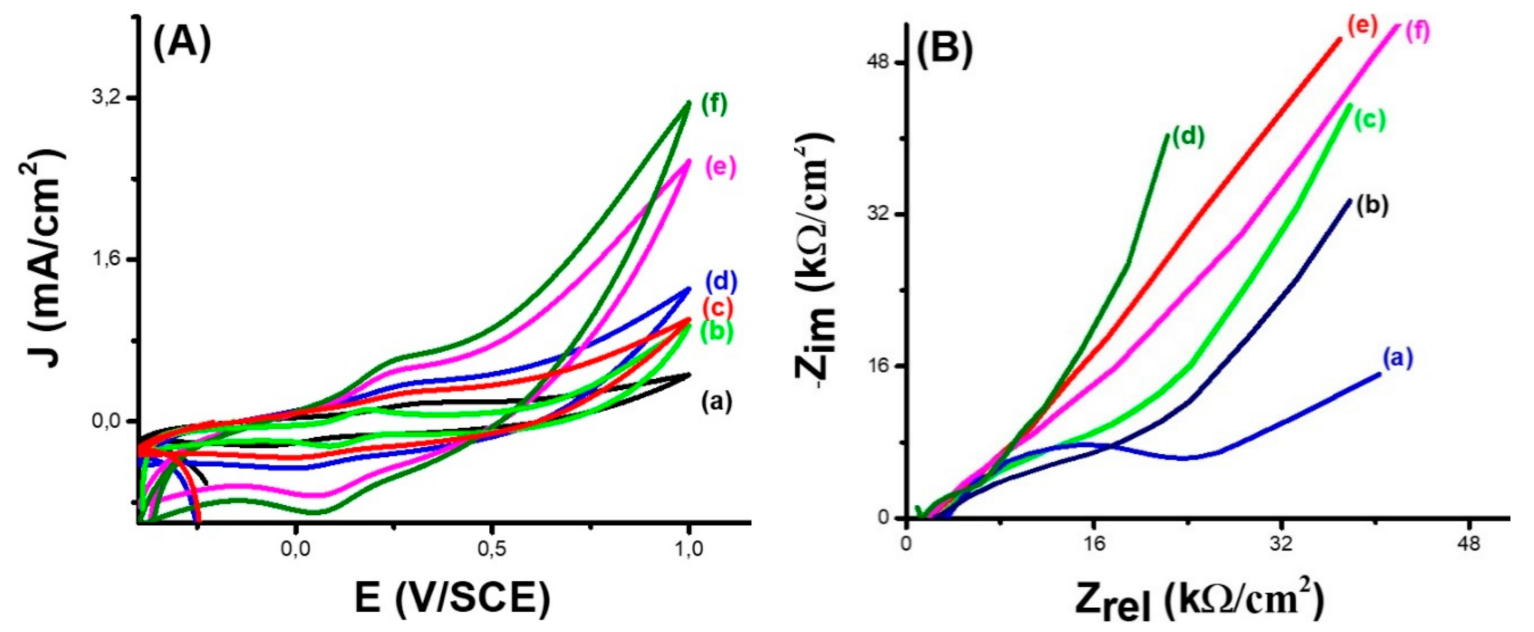

Figure 6. PPy-BSA film on (a) ITO-SO ${ }_{3} \mathrm{H}$, (b) ITO-CN, (c) ITO-CO $\mathrm{CO}_{2} \mathrm{H}$, (d) ITO-NH-Ph, (e) $\mathrm{ITO}-\mathrm{NH}_{2}$, (f) ITO-N $\left(\mathrm{CH}_{3}\right)_{2}$. (A) Blocking effect of the PPy-ABS films on the ITO electrodes modified by the different diazonium cations. (B) Impedance measurements recorded for PPy-ABS coatings on modified ITO sheets.

\subsubsection{XPS Characterization of PPy Top Coats and Reference Materials}

Figure 7 displays survey regions of ITO, ITO-SO ${ }_{3} \mathrm{H}, \mathrm{ITO}-\mathrm{N}\left(\mathrm{CH}_{3}\right)_{2}$, ITO-N $\left(\mathrm{CH}_{3}\right)_{2}$-PPy samples in the 100-600 eV range. S2p, C1s, N1s, and In3d/Sn3d doublets are centered at 168, 285, 400, 445-453 and $487-496 \mathrm{eV}$, respectively.

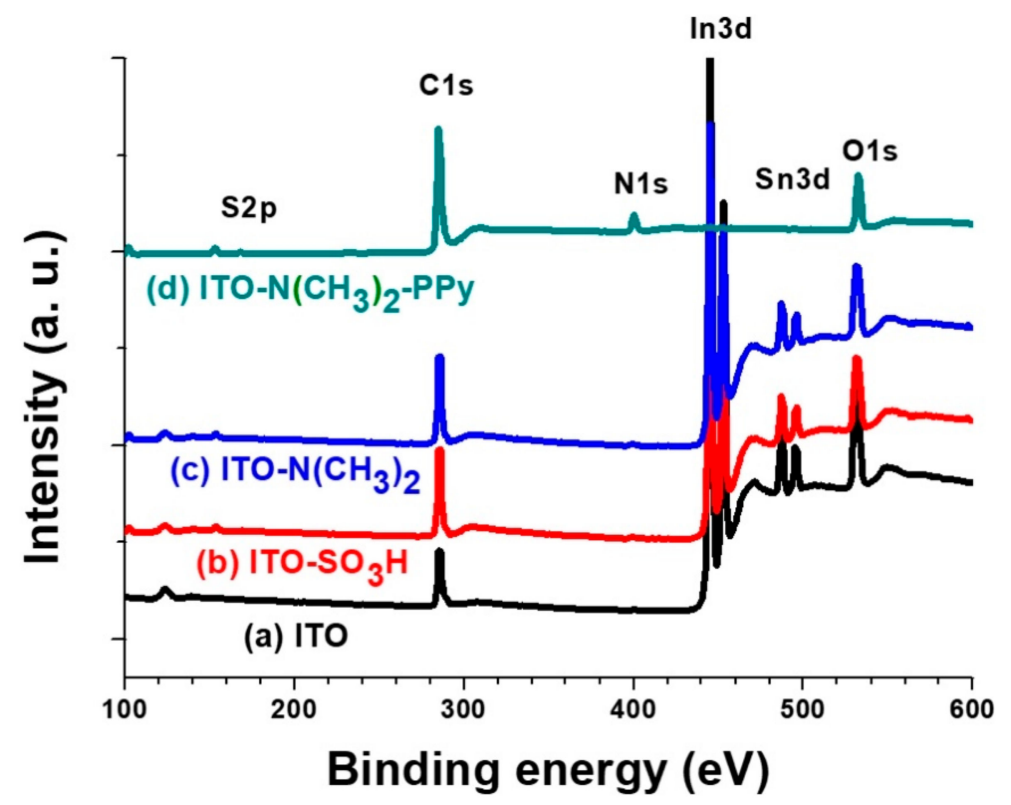

Figure 7. XPS survey regions of (a) ITO, (b) ITO-SO $3 \mathrm{H}$, (c) ITO-N $\left(\mathrm{CH}_{3}\right)_{2}$ and (d) ITO-N $\left(\mathrm{CH}_{3}\right)_{2}-\mathrm{PPy}$.

Bare ITO (Figure 7a) exhibits a quasi-horizontal background in the 160-285 eV spectral region and a sharp In3d doublet together with Sn3d peaks. Attachment of an aryl monolayer screened ITO (Figure $7 \mathrm{~b}, \mathrm{c}$ ) therefore resulting in an increase of the relative $\mathrm{C} 1 \mathrm{~s}$ peak intensity, and in the appearance 
of an S2p peak at $\sim 168 \mathrm{eV}$ for ITO-SO ${ }_{3} \mathrm{H}$ (Figure $7 \mathrm{~b}$ ) and of a N1s peak at $400 \mathrm{eV}$ for ITO-N $\left(\mathrm{CH}_{3}\right)_{2}$ (Figure 7c). After electropolymerization, the survey region resembled that of pure polypyrrole with effective screening of the characteristic In3d and Sn3d features from ITO (Figure 7d).

All apparent compositions (in at. \%) are reported in Table 2 for the main elements. The carbon and nitrogen contents increased in the order ITO $<$ ITO-aryl $<$ ITO-aryl-PPy. Sulfur content is due to the sulfonate group from ITO- $\mathrm{SO}_{3} \mathrm{H}$, and to all PPy-BSA topcoats. This sulfur content is invariably higher for PPy-BSA than for ITO-SO ${ }_{3} \mathrm{H}$. In contrast, there is a clear decrease for the $\mathrm{O}$ at. \%, as one shifts from ITO to ITO-aryl, then PPy. Indium and tin atoms are detected for bare and aryl-modified ITO surfaces only. After electropolymerization, In and Sn could not be detected since XPS is surface specific technique (about 12-15 nm depth) while PPy topcoat thickness is in the micrometer scale range ( $\sim 3 \mu \mathrm{m}$, SEM image not shown). This is a much too large thickness for a topcoat to possibly detect the buried layers using XPS (10-12 nm sampling depth for organic coatings).

Table 3 provides also the In4d/In3d intensity ratio for bare and aryl-modified ITO sheets. Invariably, this ratio is higher for the modified ITO sheets. Indeed, an aryl layer screens ITO, but at a different extent for the In $4 \mathrm{~d}$ and In3d core electrons. The sampling depth of In $4 \mathrm{~d}$ is about $12.6 \mathrm{~nm}$ higher than that of In3d (10.8 nm) [47]. It follows that In3d peak attenuation is larger, hence In4d/In3d intensity ratio increases upon aryl grafting. All aryl layers have nanometer scale thickness well below $10.8 \mathrm{~nm}$ (the sampling depth of In3d).

Table 3. XPS-determined apparent surface chemical composition of ITO, ITO-aryl and ITO-aryl-PPy samples.

\begin{tabular}{cccccccc}
\hline Materials & $\mathbf{C}$ & $\mathbf{N}$ & $\mathbf{S}$ & $\mathbf{O}$ & $\mathbf{I n}$ & $\mathbf{S n}$ & In4d/In3d \\
\hline ITO & 32.5 & - & - & 39.1 & 25.4 & 3.06 & 0.155 \\
ITO-SO $_{3} \mathrm{H}$ & 45.2 & 0.77 & 1.00 & 30.0 & 20.5 & 2.43 & 0.167 \\
ITO-SO $_{3} \mathrm{H}-\mathrm{PPy}$ & 73.9 & 9.29 & 1.38 & 15.4 & - & - & \\
ITO-COOH & 58.6 & 1.68 & - & 25.1 & 11.3 & 3.34 & 0.174 \\
ITO-COOH-PPy & 78.7 & 10.5 & 1.13 & 9.71 & - & - & \\
ITO-CN & 71.4 & 4.91 & - & 16.8 & 5.88 & 1.04 & 0.179 \\
ITO-CN-PPy & 75.2 & 9.23 & 2.12 & 13.5 & - & - & \\
ITO-NH-Ph & 49.2 & 1.97 & - & 29.6 & 16.2 & 3.05 & 0.171 \\
ITO-NH-Ph-PPy & 75.5 & 9.83 & 1.71 & 12.9 & - & - & \\
ITO-NH & 42.9 & 1.31 & - & 33.1 & 16.2 & 6.55 & 0.159 \\
ITO-NH $-\mathrm{PPy}$ & 77.3 & 12.2 & 2.22 & 8.22 & - & - & \\
ITO-N $\left(\mathrm{CH}_{3}\right)_{2}$ & 52.7 & 1.13 & - & 28.2 & 15.5 & 2.48 & 0.181 \\
ITO-N $\left(\mathrm{CH}_{3}\right)_{2}-\mathrm{PPy}$ & 76.5 & 6.94 & 1.18 & 15.4 & - & - & \\
\hline
\end{tabular}

As the blocking effect can be due to the thickness or grafting density of the top layer, we were tempted to correlate $I_{\text {rel }}$ (in Table 1) to $I_{4 \mathrm{~d}} / I_{3 \mathrm{~d}}$ XPS intensity ration (in Table 3 ). The correlation is poor and the data corresponding to ITO-NH ${ }_{2}\left(I_{4 \mathrm{~d}} / I_{3 \mathrm{~d}}=0.159 ; I_{\text {rel }}=46.6 \%\right)$ differs markedly from the trend given by the 5 other surfaces. As a matter of fact, Baranton and Bélanger [48] clearly indicated that blocking effect cannot be simply related to the film thickness or the surface coverage. Herein, we do confirm such an observation previously reported [48] and confirm that the hydrophilic/hydrophobic effects operate at the interface, which gives full credit to Downard and Prince [49]. It follows that barrier properties cannot be interpreted simply in terms of coverage or thickness; herein we demonstrate that barrier properties are very likely to be correlated to the hydrophobic/hydrophilic character of the ITO-aryl surfaces as shown in Figure 4a,b.

\subsection{Practical Adhesion Aspects of Polypyrrole Thin Layers}

Practical adhesion of PPy thin layers has been qualitatively investigated by solvent washing, ultrasonication and bend stress. Simple solvent washing using a laboratory wash bottle demonstrates the efficiency of the diazonium adhesive layer in anchoring PPy to ITO. This is shown in a video available in the Supplementary Material SM Video1. This video shows that without any aryl adhesive 
layer, PPy is simply and easily removed upon washing with deionized water. The middle part of the video (starting at $0.48 \mathrm{~min}$ ) shows that another PPy film grown on bare ITO is very easily delaminated using tweezers. In the last part of the video (starting at $1.07 \mathrm{~min}$ ), prolonged washing of PPy topcoat of ITO- $\mathrm{NH}_{2}$ electrode does not induce any adhesion failure. We have then compared adhesion of PPy to bare ITO and ITO- $\mathrm{NH}_{2}$ using ultrasonication (video not shown): again, the aryl layer prevents adhesion failure of the PPy, whereas on bare ITO the film is removed previously reported [22]. Actually, the removal of PPy from ITO- $\mathrm{NH}_{2}$ was only possible through scratching. Such robust adhesion of polypyrrole to aminophenyl-grafted glassy carbon electrode found by Patterson and Ignaszak [23] confirms our previous findings on ITO- $\mathrm{NH}_{2}$ and supports the actual work which generalizes the strong adhesion of polypyrrole to flexible ITO and other electrodes.

One of the important aspects of polymer adhesion is to define the type of adhesion bonding. In a previous publication, Samanta et al. [47] have demonstrated that photochemically-prepared $\mathrm{PPy} /$ silver nanocomposite film was removed using adhesive tape from bare ITO, whereas no failure occurred in the case of pyrrole-functionalized ITO sheets. A failure within the polymer film is defined as "cohesive failure". Herein, ultrasonication of ITO-PPy resulted in the delamination of the conductive polymer topcoat. XPS inspection of the ITO fracture surface, after ITO-PPy adhesion failure, brought strong supporting evidence for a neat ITO surface without any attenuation of the characteristic peaks from ITO (see Survey region in Figure 8a). It is worthwhile to note that the C1s peak is weakly intense and is partly due to unavoidable adventitious contamination during the transfer from atmosphere to the vacuum chamber of the XPS apparatus. The spectrum displayed in Figure 8a is a clear sign of an "adhesive failure", ca exactly at the ITO-PPy interface. Both materials are split apart upon ultrasonication.
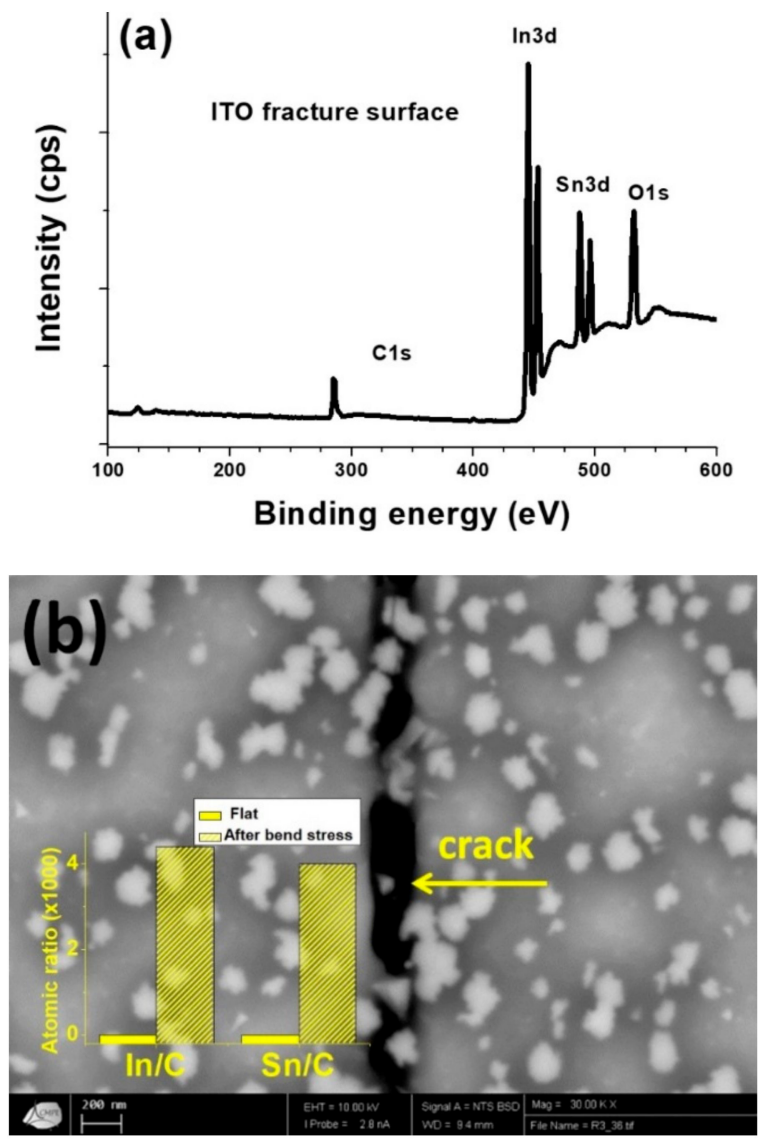

Figure 8. Adhesion testing of polypyrrole thin films on (a) bare ITO using XPS; and (b) ITO-NH $\mathrm{NH}_{2}$ using $\mathrm{SEM}$ and XPS. Inset of $8 \mathrm{~b}$ shows the bar graph of In/C atomic. 
We also examined the propensity of the ITO- $\mathrm{NH}_{2}-\mathrm{PPy}$ hybrid electrodes to withstand bending stress. The ITO-NH $2-\mathrm{PPy}$ test electrode was prepared as described above and stuck on the outer wall of a tube for $24 \mathrm{~h}$ bending stress; the bending radius was $3.2 \mathrm{~mm}$ as measured using an electronic digital caliper (Fowler, model S225; Newton, MA, USA). This is a small radius and accounts for an important stress [20]. Compared to the unbent sample, the PPy film withstood the very high bending stress and remained stuck to the underlying ITO- $\mathrm{NH}_{2}$ substrate. However, we found a slight increase in the In/C and $\mathrm{Sn} / \mathrm{C}$ atomic ratios, which probably resulted from a possible diffusion of In and $\mathrm{Sn}$ in the top coat. Indeed, SEM inspection of the ITO- $\mathrm{NH}_{2}$-PPy surface after bending showed a crack in the ITO layer (Figure $8 b$ ).

From these qualitative tests, clearly the conductive polymer films strongly adhere to the ITO surface due to the molecular interactions that operate at interfaces between PPy and all diazonium-modified ITO flexible electrodes. The aryl groups were shown to be bridged to the oxide surface through metal-O-C bonds [54,55]. We have selected functional groups in para position, that undergo either electrostatic interactions or electron-donor/acceptor bonds (Figure 9). Although not covalent in nature, these interfacial interactions are sufficiently strong to keep PPy anchored to the ITO via the aryl layer. The deposition of PPy on aryl-modified ITO is simple, fast, and provides strong adhesion that withstands severe conditions, even under high mechanical stress. This contrasts with the poor adhesion of polypyrrole to bare ITO, as previously reported in the literature [19].<smiles>CC(C)S(=O)(=O)[O-]</smiles><smiles>Cc1ccc(C)[nH]1</smiles>

Electrostatic<smiles></smiles>

Hydrogen bonding

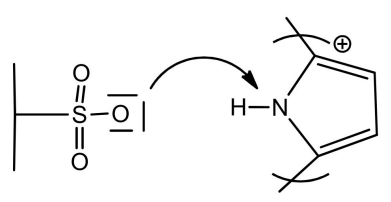

$\mathrm{n} \longrightarrow \sigma^{*}$<smiles></smiles>

Hydrogen bonding

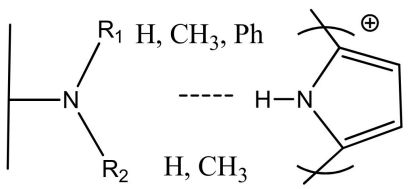

Hydrogen bonding

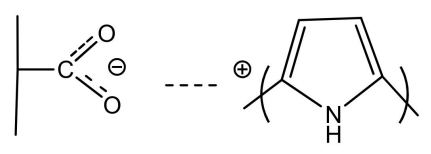

Electrostatic<smiles>Cc1cc(C(C)(C)C)c(C)[nH]1</smiles>

Hydrogen bonding<smiles>Cc1ccc(C(C)C)n1NCCCCCC(=O)C(C)C</smiles>

$\mathrm{n} \longrightarrow \sigma^{*}$

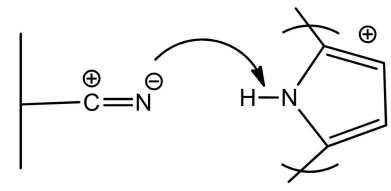

$\mathrm{n} \longrightarrow \sigma^{*}$

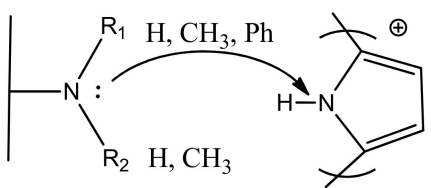

$\mathrm{n} \longrightarrow \sigma^{*}$

Figure 9. Possible molecular interactions at aryl-polypyrrole interfaces. 


\section{Conclusions}

In this work, flexible ITO sheets were grafted using in situ-generated diazonium salts bearing electron acceptor $\left(\mathrm{COOH}, \mathrm{SO}_{3} \mathrm{H}\right.$ and $\left.\mathrm{CN}\right)$ or electron-donor $\left(\mathrm{NH}_{2}, \mathrm{~N}\left(\mathrm{CH}_{3}\right)_{2}, \mathrm{NH}\right.$-Phenyl) groups. We have carefully grafted monolayers which were thin enough to prevent passivation but which permitted to prepare adherent polypyrrole top coatings by electropolymerization. The aryl layers were characterized by contact angle measurements and by XPS. Interestingly, the blocking effects and charge transfer resistance of the aryl layers were correlated with their hydrophobic character. All aryl layers served as remarkable coupling agents for the polypyrrole top coats which withstand sonication, solvent washing and bend stress. On bare ITO, PPy could be removed by simple washing with water or using tweezers, without any trace of polymer left on the surface as judged from XPS analysis of the fracture surface. This accounts for adhesive failure of the coating. In contrast, on all aryl-modified ITO sheets no delamination took place, and the polymer could be only removed by scratching the polypyrrole film. The adherent polypyrrole exhibited a better redox activity in terms of high current output on the most hydrophobic surfaces obtained with aminated, electron-donor groups, thus indicating the possibility to tune both the adhesion strength and redox properties of the conductive polymer. Adhesion of polypyrrole to ITO via aryl layers, is likely to be due to interfacial electrostatic interactions between the electron acceptor groups $\mathrm{COOH} / \mathrm{COO}^{-}, \mathrm{SO}_{3} \mathrm{H} / \mathrm{SO}_{3} \mathrm{H}$ and $\mathrm{CN} / \mathrm{C}^{+}=\mathrm{N}^{-}$and the polypyrrole positively charged backbone. As far as the nitrogen-containing electron-donor groups, such as $\mathrm{NH}_{2}$, $\mathrm{N}\left(\mathrm{CH}_{3}\right)_{2}$ and NH-Phenyl, are concerned, the adhesion is attributed to $\mathrm{n}-\sigma^{*}$ electron-donor-acceptor interactions (the pyrrole $\mathrm{N}-\mathrm{H}$ bond being the $\sigma^{*}$ acceptor).

This work sheds a new light on the use of diazonium salts to make adhesive primer layers for electroactive polymers and other organic coatings. As silanes in the 20th century, so diazonium salts could be regarded as magic molecular glues for tuning interfacial properties of next generation advanced materials of relevance to sensors, printed soft electronics and flexible thermoelectrics to name but these timely remarkable applications.

Supplementary Materials: The following are available online at http:/ / www.mdpi.com/2571-9637/1/1/5/s1.

Author Contributions: Conceptualization of the research work by M.L., M.M.C., D.G.-S. and K.D.; Methodology by M.L. and M.M.C.; Validation by M.M.C., K.D., D.G.-S., J.-J.A.; Formal Analysis by M.L., R.P., M.M.C.; Writing of Original Draft was done by M.L. and M.M.C.; Writing: Review and Editing, M.L., M.M.C., J.-J.A. and M.A.O.; Supervision, M.M.C. and D.G.-S.; Funding Acquisition, J.-J.A., M.A.O. and D.G.-S.

Funding: One of us (Momath Lo) gratefully thanks the Cooperation and Cultural Action Service of the French Embassy in Senegal for a PhD grant.

Acknowledgments: All authors thank S. Chehimi (EFREI, Villejuif, France) for the video making presented as Supplementary Material.

Conflicts of Interest: The authors declare no conflict of interest.

\section{References}

1. MacDiarmid, A.G. Polyaniline and polypyrrole: Where are we headed? Synth. Met. 1997, 84, 27-34. [CrossRef]

2. George, P.M.; Lyckman, A.W.; LaVan, D.A.; Hegde, A.; Leung, Y.; Avasare, R.; Testa, C.; Alexander, P.M.; Langer, R.; Sur, M. Fabrication and biocompatibility of polypyrrole implants suitable for neural prosthetics. Biomaterials 2005, 26, 3511-3519. [CrossRef] [PubMed]

3. Bharti, M.; Singh, A.; Samanta, S.; Debnath, A.K.; Aswal, D.K.; Muthe, K.P.; Gadkari, S.C. Flexo-green Polypyrrole-Silver nanocomposite films for thermoelectric power generation. Energy Convers. Manag. 2017, 144, 143-152. [CrossRef]

4. Sun, X.; Zhang, H.; Zhou, L.; Huang, X.; Yu, C. Polypyrrole-coated zinc ferrite hollow spheres with improved cycling stability for lithium-ion batteries. Small 2016, 12, 3732-3737. [CrossRef] [PubMed]

5. Omastová, M.; Trchová, M.; Kovárová, J.; Stejskal, J. Synthesis and structural study of polypyrroles prepared in the presence of surfactants. Synth. Met. 2003, 138, 447-455. [CrossRef] 
6. Sadki, S.; Schottland, P.; Brodie, N.; Sabouraud, G. The mechanisms of pyrrole electropolymerization. Chem. Soc. Rev. 2000, 29, 283-293.

7. Cruz-Silva, R.; Amaro, E.; Escamilla, A.; Nicho, M.E.; Sepulveda-Guzman, S.; Arizmendi, L.; Romero-Garcia, J.; Castillon-Barraza, F.F.; Farias, M.H. Biocatalytic synthesis of polypyrrole powder colloids and films using horseradish peroxidase. J. Colloid Interface Sci. 2008, 328, 263-269. [CrossRef] [PubMed]

8. Saad, A.; Cabet, E.; Lilienbaum, A.; Hamadi, S.; Abderrabba, M.; Chehimi, M.M. Polypyrrole/Ag/mesoporous silica nanocomposite particles: Design by photopolymerization in aqueous medium and antibacterial activity. J. Taiwan Inst. Chem. Eng. 2017, 80, 1022-1030. [CrossRef]

9. Hamouma, O.; Oukil, D.; Omastová, M.; Chehimi, M.M. Flexible paper@carbonnanotube@polypyrrole composites: The combined pivotal roles of diazonium chemistry and sonochemicalpolymerization. Colloids Surf. Physicochem. Eng. Asp. 2018, 538, 350-360. [CrossRef]

10. Omastová, M.; Mičušík, M. Polypyrrole coating of inorganic and organic materials by chemical oxidative polymerization. Chem. Pap. 2012, 66, 392-414. [CrossRef]

11. Baibarac, M.; Gómez-Romero, P. Nanocomposites based on conducting polymers and carbon nanotubes: From fancy materials to functional applications. J. Nanosci. Nanotechnol. 2006, 6, 289-302. [CrossRef] [PubMed]

12. Lee, S.; Sung, H.; Han, S.; Paik, W. Polypyrrolefilm formation by solution-surface electropolymerization: Influence of solvents and doped anions. J. Phys. Chem. 1994, 98, 1250-1252. [CrossRef]

13. Ferreira, C.A.; Aeiyach, S.; Delamar, M.; Lacaze, P.C. Electropolymerization of pyrrole on iron electrodes: Influence of solvent and electrolyte on the nature of the deposits. J. Electroanal. Chem. Interfacial Electrochem. 1990, 284, 351-369. [CrossRef]

14. Kaplin, D.A.; Qutubuddin, S. Electrochemically synthesized polypyrrolefilms: Effects of polymerization potential and electrolyte type. Polymer 1995, 36, 1275-1286. [CrossRef]

15. Raso, M.A.; González-Tejera, M.J.; Carrillo, I.; Sanchez De La Blanca, E.; García, M.V.; Redondo, M.I. Electrochemical nucleation and growth of poly-N-methylpyrrole on copper. Thin Solid Films 2015, 19, 2387-2392. [CrossRef]

16. Sharifirad, M.; Omrani, A.; Rostami, A.A.; Khoshroo, M. Electrodeposition and characterization of polypyrrolefilms on copper. J. Electroanal. Chem. 2010, 645, 149-158. [CrossRef]

17. Alfaro-López, H.M.; Aguilar-Hernandez, J.R.; Garcia-Borquez, A.; Hernandez-Perez, M.A.; Contreras-Puente, G.S. Electropolymerization of polypyrrole films in aqueous solution with side-coupler agent to hydrophobic groups. Interface Control. Org. Thin Films 2009, 129, 73-78.

18. Wang, Y.; Northwood, D.O. An investigation into the nucleation and growth of an electropolymerized polypyrrole coating on a 316L stainless steel surface. Thin Solid Films 2008, 516, 7427-7432. [CrossRef]

19. Castro-Beltran, A.; Dominguez, C.; Bahena-Uribe, D.; Sepulveda-Guzmana, S.; Cruz-Silva, R. Effect of non-electroactive additives on the early stage pyrrole electropolymerization on indium tin oxide electrodes. Thin Solid Films 2014, 566, 23-31. [CrossRef]

20. Singh, A.; Salmi, Z.; Joshi, N.; Jha, P.; Kumar, A.; Lecoq, H.; Lau, S.; Chehimi, M.M.; Aswal, D.K.; Gupta, S.K. Photo-induced synthesis of polypyrrole-silver nanocomposite films on $N$-(3-trimethoxysilylpropyl)pyrrolemodified biaxially oriented polyethylene terephthalate flexible substrates. RSC Adv. 2013, 3, 5506-5523. [CrossRef]

21. Bouktit, B.; Salmi, Z.; Decorse, P.; Lecocq, H.; Jouini, M.; Aswal, D.; Singh, A.; Chehimi, M.M. Polypyrrole/Ag nanocomposite films on diazonium salt modified indium tin oxide substrate. J. Colloid Sci. Biotechnol. 2013, 2, 200-210. [CrossRef]

22. Lo, M.; Diaw, A.K.D.; Gningue-Sall, D.; Aaron, J.-J.; Oturan, M.A.; Chehimi, M.M. The role of diazonium interface chemistry in the design of high performance polypyrrole-coated flexible ITO sensing electrodes. Electrochem. Commun. 2017, 77, 14-17. [CrossRef]

23. Patterson, N.; Ignaszak, A. Modification of glassy carbon with polypyrrole through an aminophenyl linker to create supercapacitive materials using bipolar electrochemistry. Electrochem. Commun. 2018, 93, 10-14. [CrossRef]

24. Mevellec, V.; Rousse, S.; Tessier, L.; Chancolon, J.; Mayne-L'Hermite, M.; Deniau, G.; Viel, P.; Palacin, S. Grafting polymers on surfaces: A new powerful and versatile diazonium salt-based one-step process in aqueous media. Chem. Mater. 2007, 19, 6323-6330. [CrossRef] 
25. Viel, P.; Le, X.T.; Huc, V.; Bar, J.; Benedetto, A.; Le Goff, A.; Filoramo, A.; Alamarguy, D.; Noël, S.; Baraton, L.; et al. Covalent grafting onto self-adhesive surfaces based on aryldiazonium salt seed layers. J. Mater. Chem. 2008, 18, 5913-5920. [CrossRef]

26. Alageel, O.; Abdallah, M.N.; Luo, Z.Y.; Del-Rio-Highsmith, J.; Cerruti, M.; Tamimi, F. Bonding metals to poly(methyl methacrylate) using aryldiazonium salts. Dent. Mater. 2015, 31, 105-114. [CrossRef] [PubMed]

27. Watts, J.F.; Rattana, A.; Abel, M.-L. Interfacial chemistry of adhesives on hydrated aluminium and hydrated aluminium treated with an organosilane. Surf. Interface Anal. 2004, 36, 1449-1468. [CrossRef]

28. Jesson, D.A.; Abel, M.-L.; Hay, J.N.; Smith, P.A.; Watts, J.F. Organic-inorganic hybrid nanoparticles: Surface characteristics and interactions with a polyester resin. Langmuir 2006, 22, 5144-5151. [CrossRef] [PubMed]

29. Tashiro, H.; Nakaya, M.; Hotta, A. Enhancement of the gas barrier property of polymers by DLC coating with organosilane interlayer. Diam. Relat. Mater. 2013, 35, 7-13. [CrossRef]

30. Bélanger, D.; Pinson, J. Electrografting: A powerful method for surface modification. Chem. Soc. Rev. 2011, 40, 3995-4048. [CrossRef] [PubMed]

31. Wang, J.; Firestone, M.A.; Auciello, O.; Carlisle, J.A. Surface functionalization of ultrananocrystalline diamond films by electrochemical reduction of aryldiazonium salts. Langmuir 2004, 20, 11450-11456. [CrossRef] [PubMed]

32. Mirkhalaf, F.; Graves, J.E. Nanostructured electrocatalysts immobilised on electrode surfaces and organic film templates. Chem. Pap. 2012, 66, 472-483. [CrossRef]

33. Bakas, I.; Yilmaz, G.; Ait-Touchente, Z.; Lamouri, A.; Lang, P.; Battaglini, N.; Carbonnier, B.; Chehimi, M.M.; Yagci, Y. Diazonium salts for surface-confined visible light radical photopolymerization. J. Polym. Sci. Part A Polym. Chem. 2016, 54, 3506-3515. [CrossRef]

34. Stockhausen, V.; Nguyen, V.Q.; Martin, P.; Lacroix, J.-C. Botom-up electrochemical fabrication of conjugated ultrathin layers with tailored switchable properties. ACS Appl. Mater. Interfaces 2017, 9, 610-617. [CrossRef] [PubMed]

35. Wang, Y.; Fantin, M.; Park, S.; Gottlieb, E.; Fu, L.; Matyjaszewski, K. Electrochemically mediated reversible addition-fragmentation chain-transfer polymerization. Macromolecules 2017, 50, 7872-7879. [CrossRef] [PubMed]

36. Gui, A.L.; Luais, E.; Peterson, J.R.; Godding, J.J. Zwitterionic phenyl layers: Finally, stable, anti-biofouling coatings that do not passivate electrodes. ACS Appl. Mater. Interfaces 2013, 5, 4827-4835. [CrossRef] [PubMed]

37. Cao, C.; Zhang, Y.; Jiang, C.; Qi, M.; Liu, G. Advances on aryldiazonium salt chemistry based interfacial fabrication for sensing applications. ACS Appl. Mater. Interfaces 2017, 9, 5031-5049. [CrossRef] [PubMed]

38. Guselnikova, O.; Postnikov, P.; Elashnikova, R.; Trusova, M.; Kalachyova, Y.; Libansky, M.; Barek, J.; Kolska, Z.; Švorčík, V.; Lyutakov, O. Surface modification of Au and Ag plasmonic thin films via diazonium chemistry: Evaluation of structure and properties. Colloids Surf. A Physicochem. Eng. Asp. 2017, 516, 274-285. [CrossRef]

39. Jlassi, K.; Chandran, S.; Poothanari, M.A.; Benna-Zayani, M.; Thomas, S.; Chehimi, M.M. Clay/polyaniline hybrid through diazonium chemistry: Conductive nanofiller with unusual effects on interfacial properties of epoxy nanocomposites. Langmuir 2016, 32, 3514-3524. [CrossRef] [PubMed]

40. Sandomierski, M.; Strzemiecka, B.; Chehimi, M.M.; Voelkel, A. Reactive diazonium-modified silica fillers for high-performance polymers. Langmuir 2016, 32, 11646-11654. [CrossRef] [PubMed]

41. Jacques, A.; Chehimi, M.M.; Poleunis, C.; Delcorte, A.; Delhalle, J.; Mekhalif, Z. Grafting of 4-pyrrolyphenyldiazonium in situ generated on $\mathrm{NiTi}$, an adhesion promoter for pyrrole electropolymerisation. Electrochim. Acta 2016, 211, 879-890. [CrossRef]

42. Kullapere, M.; Mirkhalaf, F.; Tammeveski, K. Electrochemical behaviour of glassy carbon electrodes modified with aryl groups. Electrochim. Acta 2010, 56, 166-173. [CrossRef]

43. Jacques, A.; Devillers, S.; Delhalle, J.; Mekhalif, Z. Electrografting of in situ generated pyrrole derivative diazonium salt for the surface modification of nickel. Electrochim. Acta 2013, 109, 781-789. [CrossRef]

44. Shul, G.; Weissmann, M.; Bélanger, D. Electrochemical characterization of glassy carbon electrode modified with 1,10-phenanthroline groups by two pathways: Reduction of the corresponding diazonium ions and reduction of phenanthroline. Electrochim. Acta 2015, 162, 146-155. [CrossRef]

45. Seck, S.M.; Charvet, S.; Fall, M.; Baudrin, E.; Geneste, F.; Lejeune, M.; Benlahsen, M. Functionalization of amorphous nitrogenated carbon thin film electrodes for improved detection of cadmium vs. copper cations. J. Electroanal. Chem. 2015, 738, 154-161. [CrossRef] 
46. Jiang, C.; Moraes Silva, S.; Fan, S.; Wu, Y.; Tanzirul Alam, M.; Liu, G.; Gooding, J.J. Aryldiazonium salt derived mixed organic layers: From surface chemistry to their applications. J. Electroanal. Chem. 2017, 785, 265-278. [CrossRef]

47. Samanta, S.; Bakas, I.; Singh, A.; Aswal, D.K.; Chehimi, M.M. In situ diazonium-modified flexible ITO-coated PEN substrates for the deposition of adherent silver-polypyrrole nanocomposite films. Langmuir 2014, 30, 9397-9406. [CrossRef] [PubMed]

48. Baranton, S.; Belanger, D. Electrochemical derivatization of carbon surface by reduction of in situ generated diazonium cations. J. Phys. Chem. B 2005, 109, 24401-24410. [CrossRef] [PubMed]

49. Downard, A.J.; Prince, M.J. Barrier properties of organic monolayers on glassy carbon electrodes. Langmuir 2001, 17, 5581-5586. [CrossRef]

50. Wu, J.-S.; Gu, D.-W.; Huang, D.; Shen, L.-J. Chemical in situ polymerization of polypyrrole nanoparticles on the hydrophilic/hydrophobic surface of $\mathrm{SiO}_{2}$ substrates. Synth. React. Inorg. Met. Org. Nano Met. Chem. 2012, 42, 1064-1070. [CrossRef]

51. Wang, P.C.; Huang, Z.; MacDiarmid, A.G. Critical dependency of the conductivity of polypyrrole and polyaniline films on the hydrophobicity/hydrophilicity of the substrate surface. Synth. Met. 1999, 101, 852-853. [CrossRef]

52. Perruchot, C.; Chehimi, M.M.; Delamar, M.; Cabet-Deliry, E.; Miksa, B.; Slomkowski, S.; Khan, M.A.; Armes, S.P. Chemical deposition and characterization of thin polypyrrole films on glass plates: Role of organosilane treatment. Colloid Polym. Sci. 2000, 278, 1139-1154. [CrossRef]

53. Azioune, A.; Chehimi, M.M.; Miksa, B.; Basinska, T.; Slomkowski, S. Hydrophobic protein-polypyrrole interactions: The role of van der Waals and Lewis acid-base forces as determined by contact angle measurements. Langmuir 2002, 18, 1150-1156. [CrossRef]

54. AïtAtmane, Y.; Sicard, L.; Lamouri, A.; Pinson, J.; Sicard, M.; Masson, C.; Nowak, S.; Decorse, P.; Piquemal, J.-Y.; Galtayries, A.; et al. Functionalization of aluminum nanoparticles using a combination of aryl diazonium salt chemistry and iniferter method. J. Phys. Chem. C 2013, 117, 26000-26006. [CrossRef]

55. Jacques, A.; Devillers, S.; Arrotin, B.; Delhalle, J.; Mekhalif, Z. Polyelectrolyte multilayers deposition on Nitinol modified by in situ generated diazonium in gentle conditions. J. Electrochem. Soc. 2014, 161, G55-G62. [CrossRef] 